\title{
Influence of Propanol as Additive with Diesel Jatropha Biodiesel Blend Fuel for Diesel Engine
}

\author{
Abu Saleh Ahmed ${ }^{\mathrm{a}}$, Nur Adibah Abdul Rahim ${ }^{\mathrm{b},{ }^{*}}$, Md Rezaur Rahman ${ }^{\mathrm{b}}$ and Mohammad \\ Shahril Osman ${ }^{\mathrm{a}}$ \\ ${ }^{a}$ School of Engineering and Technology, University College of Technology Sarawak, 96000 \\ Sibu, Sarawak, Malaysia \\ ${ }^{\mathrm{b}}$ Faculty of Engineering, Universiti Malaysia Sarawak, 94300 Kota Samarahan, Sarawak, \\ Malaysia.
}

\begin{abstract}
Fossil fuels are widely recognized as non-renewable energy resources. They play an important role in our daily life because they can be used in various applications such as the production of soap and cosmetics, as an energy source and for transportation. However, the use of these fossil fuels causes negative impacts on humans, animals and the environment. These happen due to the emission of harmful gases into the atmosphere. Not only that, the available fossil fuels are decreasing due to continuous usage by humans. As a result, researchers investigated finding alternative ways to overcome this issue by replacing diesel fuel with biodiesel. Biodiesel is more environmentally friendly relative to diesel fuel. A research study was conducted involving biodiesel. The purpose of this study was to produce Jatropha Biodiesel, as well as evaluate the properties of Jatropha biodiesel and diesel Jatropha biodiesel blended with propanol. The production of Jatropha Biodiesel was done by using two-step transesterification which was an acid-catalyzed transesterification and base-catalyzed transesterification. Different methanol to oil ratios had been used to identify the best ratio to reduce the FFA content in the CJO. 9:1 was the best methanol to oil ratio and then tested with different catalyst weights. It was found that an increase in the weight of catalyst might reduce the amount of biodiesel yield. In addition, this study also investigated and predicted the engine performance and characteristics of diesel Jatropha biodiesel blended with propanol at different blending ratios. The properties of these test fuels were studied. Bomb calorimeter, Fourier Transform Infrared Spectroscopy (FT-IR) analysis and Diesel Engine test were done. Thus, the calorific value and functional group of the test fuels were identified and determined. The calorific value of biodiesel was much higher than conventional diesel due to the existence of oxygen. This could be proven as the analysis of FT-IR also showed a $(C=O)$ bond which reflected the presence of oxygen. The oxygen helped in combustion besides reducing the hydrocarbon released into the air. These findings were then reflected and related to the performance of diesel engines.
\end{abstract}

Keywords: Additives, Combustion, Environment, Fossil fuels, Jatropha biodiesel.

\section{Introduction}

Fossil fuels are widely recognized as non-renewable energy resources. According to Gude \& Grant (2019), the United States (U.S.) used diesel fuel for transportation purposes. It was reported that

\footnotetext{
* Corresponding author.

E-mail address: nuradibahabdrahim@gmail.com

Manuscript History:

Received 26 June, 2021, Revised 8 October, 2021, Accepted 8 October, 2021, Published 31 October, 2021

Copyright (C) 2021 UNIMAS Publisher. This is an open access article under the CC BY-NC-SA 4.0 license. https://doi.org/10.33736/jaspe.3570.2021
}

e-ISSN: 2289-7771

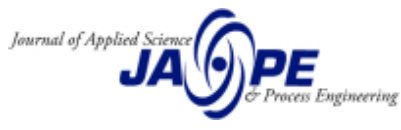


Americans consumed about 50 billion gallons of diesel fuel [1]. In addition, the U.S. imported about $65 \%$ of these fuels from other countries. Starting from 2007, the United States Government Accountability Office (U.S. GAO) discovered that there was a fluctuation regarding oil production. Thus, they had to develop a strategy in order to address and overcome this issue.

These fuels contribute a lot to the world energy supply. However, some authors argued regarding the production of fuel and its use. This included environmental concerns and political debates. Kannahi \& Arulmozhi (2013), reported that combustion of fuel contributed to $98 \%$ of carbon emission. The main drawback of using diesel fuels is atmospheric pollution [2]. Furthermore, the combustion of diesel releases numerous greenhouse gases. In short, continuous and cumulative use of diesel increases air pollution and worsens the problem of global warming. Air contaminants produced by diesel include carbon monoxide (CO), hydrocarbon $(\mathrm{HC})$, nitrogen oxide (NOx), particle pollution and volatile organic compounds.

Ogunwole OA (2012) emphasized that over many years, the use of these energy sources has led to an increase in global temperature rates, also known as global warming [3]. This happens as there is a very high level of carbon that is released as by-products and exhaust gases. Perera (2018) discussed more in his literature review regarding the impact of toxic air in terms of health issues. He mentioned that there were more reports of low birth weight infants or preterm infants, and children with asthma, cancer, behavioural disabilities, cognitive disabilities, mental health problems and cardiovascular diseases [4].

The usage of diesel fuel also leads to many political and socioeconomic problems around the world. Therefore, it is necessary to find other sources of fuel. Studies of biodiesel are well documented. It is also well acknowledged that biodiesel is more environmentally friendly than diesel. In addition, this has been discussed by a great number of authors in the literature that in the diesel engine, vegetable oil can perform well without the need for engine modification. However, the problems with biodiesel are its high auto-ignition temperature (AIT) and viscosity relative to diesel. Prior to this, the effect of Jatropha biodiesel mixture diesel engine additives was assessed in several studies on diesel engine efficiency and emissions. As far as we know, no previous research has studied the influence on diesel engine performance and emission of propanol with Jatropha biodiesel blend.

\section{Transesterification Process}

Saribiyik et al. (2010) believed that the transesterification method was the most common way of producing biodiesel [5]. To support this statement, Shahid et al. (2012) mentioned this method was relatively easy, could be carried out under normal circumstances besides offering better conversion efficiency and converted fuel quality [6]. In their review on biodiesel production technologies, Shemelis Nigatu Gebremariam \& Marchetti (2017) mentioned that around 7 kinds of processes of transesterification were available, namely acid-catalyzed, base-catalyzed, heterogeneous catalysis, lipase-catalyzed, supercritical, nano catalyzed and ionic liquid catalysts [7].

\subsection{Homogeneous acid-catalyzed transesterification}

The first method to produce biodiesel (ethyl ester) from palm oil using sulfuric acid and ethanol is acid-catalyzed transesterification [7]. The acid-catalyzed process involves the presence of an acid catalyst to enhance the reaction between alcohol with triglyceride. Esters (biodiesel) and glycerol are formed by this reaction. This approach has been reported as feasible and cost-effective for the production of biodiesel with high (FFA) content. Acid-catalyzed transesterification starts by immediately combining the oil with acid alcohol. It needs to be performed to ensure that separation and transesterification happen as the alcohol acts as a solvent and reagent for esterification in a single step. The typical and accessible acid catalyst is sulfonic acid, sulfuric acid and hydrochloric acid. The acid-catalyzed reaction, however, needs a longer reaction time and higher temperature compared to the base-catalyzed reaction. According to Farouk et al. (2014), failure to treat and store CJO results in

e-ISSN: $2289-7771$ 
an increase in FFA due to chemical reactions such as polymerization and hydrolysis. Determination of FFA value needs to be done to identify whether the CJO needs to undergo a one or two-step transesterification process [8]. After the acid-catalyzed transesterification process, they can reduce the FFA content by up to $1 \%$.

\subsection{Homogeneous base-catalyzed transesterification}

The base-catalyzed transesterification process involves triglyceride reactions, including alcoholic fats or oils in the presence of alkaline catalysts. Examples of base catalysts are alkaline metal alkoxides, hydroxides, and also sodium or potassium carbonates in the form of glycerol and esters (biodiesel). In addition to being less corrosive to industrial equipment, this process is much quicker than acid-catalyzed transesterification. Due to this, it is often used commercially. However, if the presence of water and FFA is very high, oil saponification will develop and will result in an incomplete reaction during alkaline transesterification with resulting emulsion formation and glycerol separation difficulties. In addition, water formation in the liquid can stop the reaction as well. Due to its high water content, the water is either produced from vegetable oil or created during the saponification reaction as triglycerides are hydrolyzed. This contributes to the high formation of FFA.

In the transesterification reaction, the base catalyst shows a much higher catalytic activity compared to acid catalysts. However, it is suitable for selective deriving biodiesel from refined oils with a low FFA content that is normally less than $0.5 \%$. A recent report by Farouk et al. (2014) concluded that potassium hydroxide $(\mathrm{KOH})$ and sodium hydroxide $(\mathrm{NaOH})$ were the major alkaline base catalysts used. They reported that the output yield of $99 \%$ was achieved by using $\mathrm{KOH}$ as the catalyst in 1 water to water concentration, 6 to $1 \mathrm{~mol}$ of methanol to oil ratio, $65^{\circ} \mathrm{C}$ reaction temperature, and 60 minutes reaction time [8]. Apart from that, it was found that $\mathrm{NaOH}$ induced more emulsion than $\mathrm{KOH}$ by using $\mathrm{NaOH}$ as a catalyst during biodiesel synthesis from waste sunflower cooking oil. This made it difficult to distinguish biodiesel from glycerine. It was advised to prepare the alkaline catalyst solution in methanol freshly to prevent the absorption of moisture and to preserve the catalytic activity.

\section{Materials and methods}

The titration method was used to assess the free fatty acid (FFA) content of the available crude Jatropha oil (CJO). As mentioned in the literature review, if the FFA content of the CJO is more than $3 \%$, it needs to undergo acid-catalyzed transesterification followed by base-catalyzed transesterification. These two processes are described as two-step transesterification. Then, it also goes through washing and purification processes. These need to be performed in order to eliminate any additional water content and contaminants in the biodiesel.

\subsection{Production of biodiesel from Jatropha oil}

The CJO needed to undergo a two-step transesterification process as the FFA content was above $3 \%$. The two-step transesterification involved two processes which were acid-catalyzed transesterification and base-catalyzed transesterification. This was followed by washing and purification of Jatropha biodiesel.

\subsubsection{Acid-catalyzed transesterification}

The primary purpose of the acid-catalyzed transesterification process was to reduce the CJO's FFA content. The materials needed during this experiment were CJO, distilled water, methanol ( $>99 \%$ pure), sodium hydroxide $(\mathrm{NaOH})$ and sulfuric acid $\left(\mathrm{H}_{2} \mathrm{SO}_{4}\right)$ with $95 \%$ to $97 \%$ concentration. In 
addition, the apparatus needed were filter paper, separating funnel, retort stand, magnetic stirrer, beakers, thermometer, weighing scale, measuring cylinder, aluminium foil and filter funnel.

During this experiment, the amount of $\mathrm{H}_{2} \mathrm{SO}_{4}$ needed for each ratio was $1 \%$ of the oil's mass. The oil's mass was set to be $100 \mathrm{~g}$. Besides that, different molar ratios of alcohol to oil were used which were $6: 1,7: 1,8: 1$ and 9:1. Firstly, the filter paper was used to filter and eliminate contaminants that existed in $100 \mathrm{ml}$ of CJO. Secondly, to remove the water content, it was poured into a beaker and then heated at $100^{\circ} \mathrm{C}$. Thirdly, a mixture of $\mathrm{H}_{2} \mathrm{SO}_{4}$ and methanol was prepared based on the catalyst to oil ratio and alcohol to oil ratio. Fourthly, the methoxide solution was heated at $60^{\circ} \mathrm{C}$ by using a magnetic stirrer. The methoxide solution needed to be heated up for 15 minutes. This was done until the mixture was homogenous. Then, the methoxide solution was poured into the beaker which contained filtered CJO. By using a magnetic stirrer, the mixture was heated at $60^{\circ} \mathrm{C}$ for 60 minutes. The mixture was allowed to settle down in a separating funnel for 2 hours. There were two different layers obtained. The upper layer represented glycerol while the bottom layer represented pre-treated oil. Next, the fraction of the methanol-water was removed and the oil was collected into the beaker. Finally, by using a magnetic stirrer, the oil was heated at $100^{\circ} \mathrm{C}$ until the oil turned into a clear fluid.

\subsubsection{Base-catalyzed transesterification}

The materials needed during this experiment were CJO, distilled water, Methanol ( $>99 \%$ pure), sodium hydroxide $(\mathrm{NaOH})$, and sulfuric acid $\left(\mathrm{H}_{2} \mathrm{SO}_{4}\right)$ with $95 \%$ to $97 \%$ concentration. Moreover, the apparatus needed were filter paper, separating funnel, retort stand, magnetic stirrer, beakers, thermometer, weighing scale, measuring cylinder, aluminium foil and filter funnel.

Firstly, the mixture of $\mathrm{NaOH}$ and methanol was prepared based on the catalyst to oil ratio and alcohol to oil ratio. Secondly, it was then heated for 15 minutes at $50^{\circ} \mathrm{C}$ by using a magnetic stirrer. Thirdly, it was transferred into a beaker that contained the pre-treated oil. The pre-treated oil referred to the one that was obtained during acid-catalyzed transesterification. Fourthly, the mixture was stirred for 120 minutes at $60^{\circ} \mathrm{C}$ with a speed of $400 \mathrm{rpm}$. Then, a separating funnel was used for separation purposes as the mixture was left for about 24 hours. After the separation was completed, it could be seen that the upper layer was glycerol while the lower layer was a methanol-water fraction.

\subsubsection{Washing and purification of Jatropha biodiesel}

During this process, the Jatropha biodiesel was washed by using distilled water. This needed to be done 3 times. In addition, the separation of Jatropha biodiesel and water was allowed for at least 30 minutes for each washing. Next, the water which was at the bottom layer of the separating funnel was removed. Then, to eliminate water content, the Jatropha biodiesel obtained was heated to $100^{\circ} \mathrm{C}$.

\subsubsection{Blending of Jatropha biodiesel}

The blending was done in order to produce diesel Jatropha Biodiesel with propanol as an additive. The sample produced needed to be B5 and B5P5. B5 meant the blending percentage of biodiesel was 5\%. Next, B5P5 referred to the mixture of diesel-biodiesel-propanol, which was blended 90-5-5\%. The materials needed for blending were Jatropha biodiesel, propanol, ethanol and distilled water. Furthermore, the apparatus needed were beakers and ultrasonicator.

Firstly, propanol was added to the measured 5\% Jatropha biodiesel. This meant that the blending percentage was 5\% and could be written as B5P5. The propanol was added depending on the required blending percentage. Secondly, the mixture was stirred. The same procedures were applied to another two samples. The flowchart of Jatropha Biodiesel production is shown in Figure 1.

e-ISSN: 2289-7771 


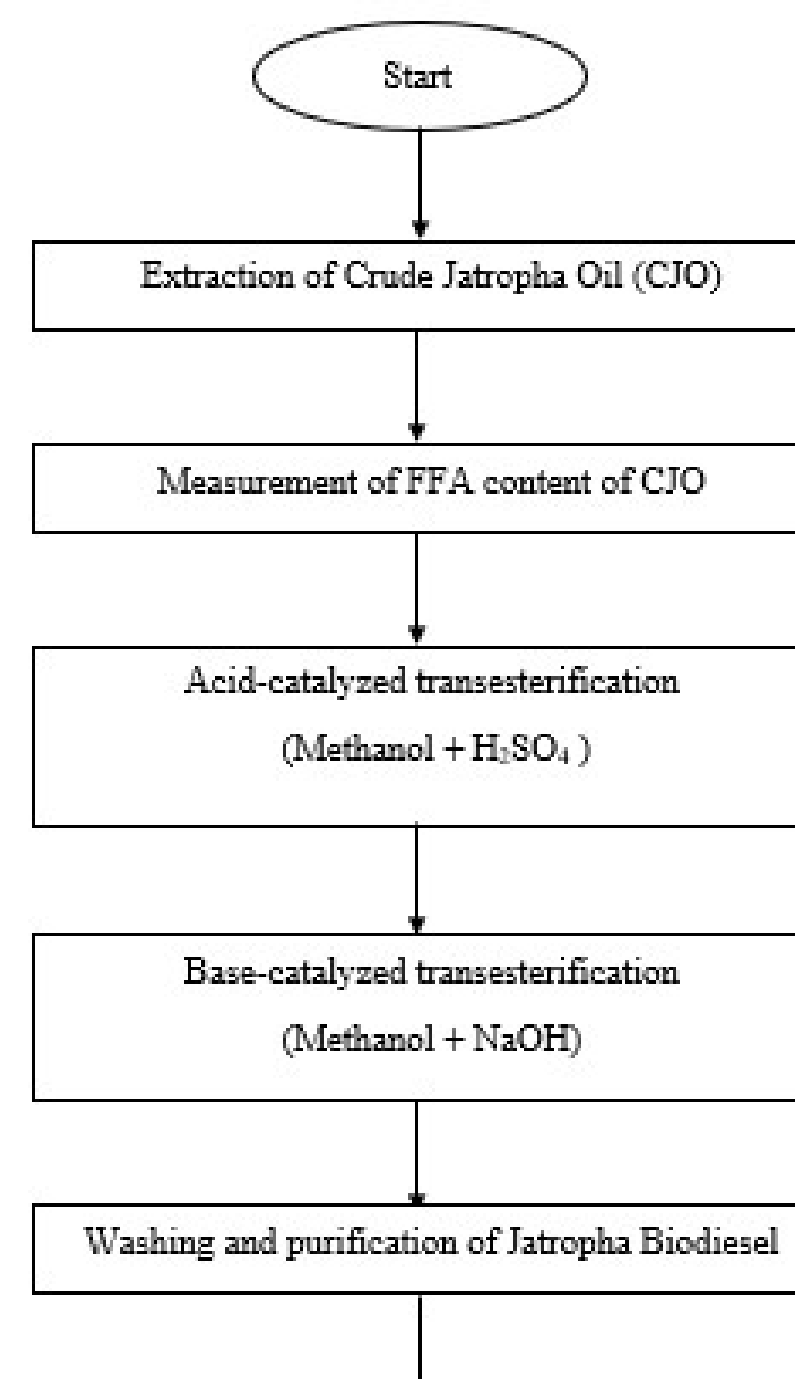

Figure 1. The flowchart of Jatropha biodiesel production.

\subsection{Characterization of Jatropha biodiesel}

Fourier Transform Infrared Spectroscopy (FT-IR), ParrTM 6400 Bomb Calorimeter, were the devices used to examine sample properties.

\subsubsection{Fourier Transform Infrared Spectroscopy (FT-IR) analysis}

The purpose of this test was to analyze the properties and composition of the samples which were CJO, B5, B5P5, Jatropha biodiesel and conventional diesel. The materials used were acetone and a sample of specimens, while the apparatus needed was Infrared Affinity-1 from Shimadzu as an FTIR spectrometer. Firstly, acetone was used to clean the surface of ATR. Secondly, a few drops of CJO were dropped on the surface of ATR. The data were recorded. The same procedures were repeated on the other samples. 


\subsubsection{Calorific value analysis}

The purpose of this testing was to identify the amounts of heat released by CJO, B5, B5P5, Jatropha biodiesel and conventional diesel combustion. The materials used were the samples while the apparatus needed was the ParrTM 6400 Bomb calorimeter.

\subsubsection{Diesel engine performance test}

This test was intended to examine the impact of samples on diesel engine performance. The materials used were the samples. The apparatus needed was a stopwatch and diesel engine.

\section{Results and discussion}

Initially, before proceeding with the transesterification process, the FFA content in CJO needed to be determined. Measurement of this FFA content was done to identify the most suitable production process of Jatropha Biodiesel. A sample with a percentage of FFA content higher than 3\% would require an additional process called esterification, involving CJO pre-treatment. The percentage of FFA content was obtained by implementing the titration method. Potassium hydroxide $0.1 \mathrm{M}$ diluted into ethanol. Table 1 shows that the percentage of FFA content for CJO was more than $3 \%$. Thus, acid-catalyzed transesterification was performed, followed by base-catalyzed transesterification to reduce the FFA content. It had to be reduced in order to form Jatropha Biodiesel. This is because, the higher the oil acidity, the poorer the efficiency of the conversion. This could lead to insufficient catalyst creation, incredibly difficult product separation and lower biodiesel yield.

Table 1. FFA measurement of CJO

\begin{tabular}{ccccc}
\hline Sample & $\begin{array}{c}\text { Volume of } \\
\text { titrant (ml) }\end{array}$ & $\begin{array}{c}\text { Mass of oil } \\
\text { sample (g) }\end{array}$ & Acid Value & FFA (\%) \\
\hline 1 & 21.4 & 3.340 & 35.95 & 18.07 \\
2 & 21.8 & 3.351 & 36.50 & 18.34 \\
3 & 21.8 & 3.283 & 37.26 & 18.72 \\
\hline
\end{tabular}

With the presence of sulfuric acid $\left(\mathrm{H}_{2} \mathrm{SO}_{4}\right)$ as the catalyst followed by another titration cycle, the CJO underwent acid-catalyzed transesterification. This included combining four oil samples with different methanol ratios to oil molar ratios (6:1, 7:1, 8:1 and 9:1) with $1 \% \mathrm{H}_{2} \mathrm{SO}_{4}$ (wt/wt of oil). The reaction temperature and time were set at $60^{\circ} \mathrm{C}$ and 60 minutes respectively. Following acid-catalyzed transesterification and heating of the CJO to remove excess moisture content, each oil sample weighed $3 \mathrm{~g}$ and then FFA content was measured again by using the titration method. Table 2 displays the FFA measurement of pre-treated Jatropha Oil when using different methanol to oil ratios. 
Table 2. The FFA measurement of pre-treated Jatropha oil with different methanol to oil ratios.

\begin{tabular}{cccccc}
\hline Ratio & Sample & $\begin{array}{c}\text { Volume of } \\
\text { titrant } \\
(\mathbf{m l})\end{array}$ & $\begin{array}{c}\text { Mass of oil } \\
\text { sample } \\
(\mathbf{g})\end{array}$ & Acid Value & FFA \\
$\mathbf{( \% )}$
\end{tabular}

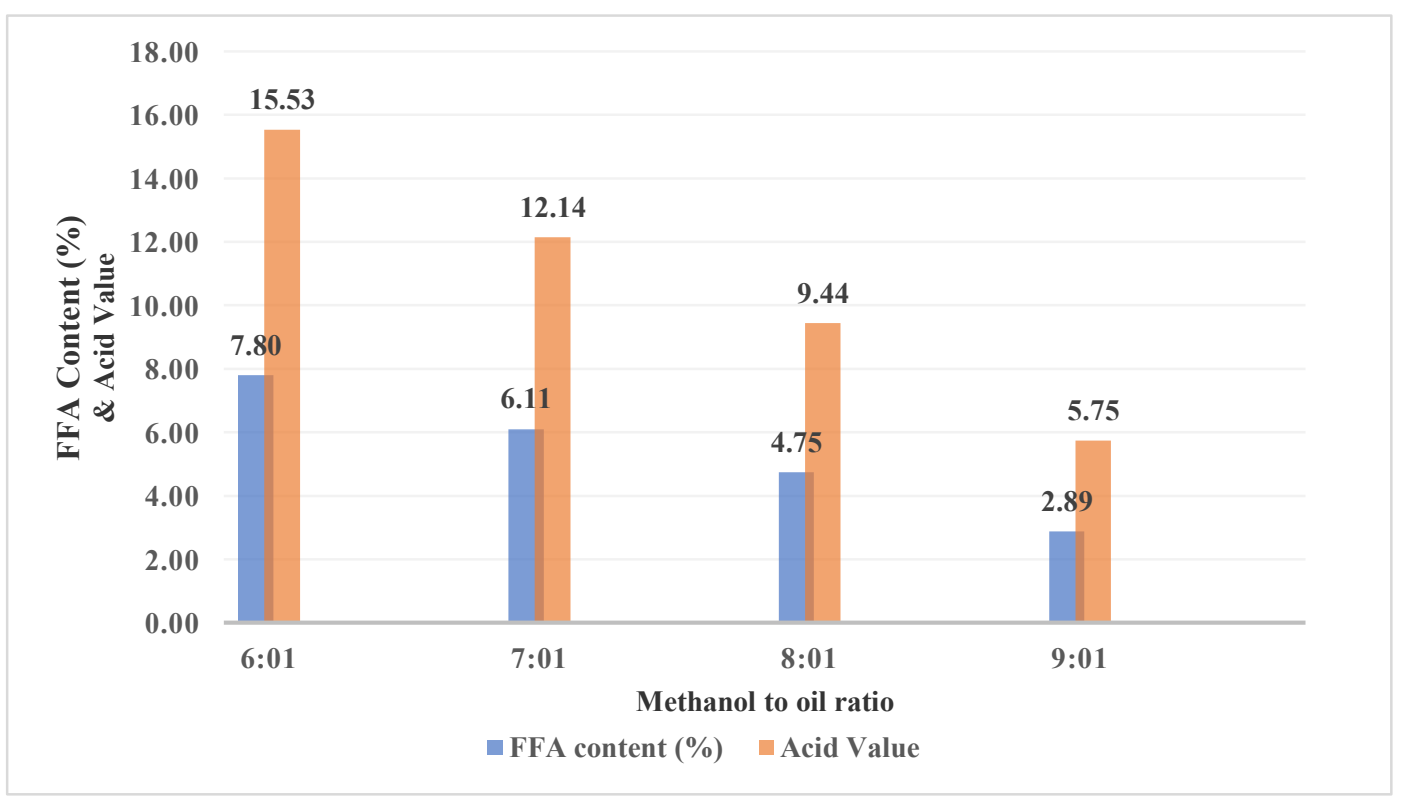

Figure 2. Bar chart of FFA content (\%) and acid value versus methanol to oil ratio. 
The lowest percentage of FFA content was obtained when the methanol to oil ratio used was $9: 1$, which was lower than $3 \%$. It was $2.89 \%$. It is clearly shown that the highest efficiency for ester production and reduction of acid value and FFA content is shown at the molar ratio of 9:1 for alcohol to oil. This was due to the fact that an optimal amount of alcohol was needed to complete the reaction. As the 9:1 ratio contributed to the lowest percentage of acid value and FFA content, this ratio was chosen to proceed with the base-catalyzed transesterification. Figure 2 demonstrates the bar chart of FFA content (\%) and acid value versus the methanol to oil ratio.

The transesterification reaction was studied in different ranges of methanol to oil ratio, which was $6: 1,7: 1,8: 1$, and 9:1. This was done to determine which ratio was able to produce the highest Jatropha Biodiesel yield. The catalyst used during base-catalyzed transesterification was Sodium Hydroxide $(\mathrm{NaOH})$. The reaction temperature and time were set at $60^{\circ} \mathrm{C}$ and an hour respectively. Table 3 shows the percentage of biodiesel yield with different weights of catalyst used.

Table 3. Percentage of biodiesel yield with different weights of catalyst.

\begin{tabular}{ccccc}
\hline $\begin{array}{c}\text { Methanol to } \\
\text { Oil ratio }\end{array}$ & $\begin{array}{c}\text { Weight of } \\
\text { Catalyst (\%) }\end{array}$ & $\begin{array}{c}\text { Weight of Pre- } \\
\text { Treated Oil (g) }\end{array}$ & $\begin{array}{c}\text { Weight of } \\
\text { Biodiesel (g) }\end{array}$ & $\begin{array}{c}\text { Biodiesel Yield } \\
\text { (\%) }\end{array}$ \\
\hline $9: 1$ & 0.2 & 200 & 145 & 72.5 \\
& 0.3 & 200 & 128 & 64 \\
& 0.4 & 200 & 116 & 58 \\
& 0.5 & 200 & 95 & 47.5 \\
\hline
\end{tabular}

Different weights of catalyst (\%) were used in order to study the effect of a catalyst on biodiesel yield. Based on the results obtained, a lower amount of $\mathrm{NaOH}$ used was able to produce higher amounts of Jatropha Biodiesel yield. From Figure 3, the increasing the weight of catalyst caused a decreasing Jatropha Biodiesel yield. Using a $0.2 \%$ weight of catalyst contributed to $72.5 \%$ of biodiesel while $0.3 \%, 0.4 \%$ and $0.5 \%$ of catalyst weight produced about $64 \%, 58 \%$ and $47.5 \%$ biodiesel yield respectively. Furthermore, it explained the development of soap as a result of the excess catalyst with a slower conversion of triglycerides into Fatty Acid Methyl Esters (FAME) that inevitably affected the yield of Jatropha biodiesel.

Table 4. Calorific values of each test fuel.

\begin{tabular}{cc}
\hline Test Fuel & Calorific Value (MJ/kg) \\
\hline Conventional Diesel & 45.5815 \\
B5 & 39.7434 \\
B5P5 & 44.4861 \\
B5P10 & 42.8386 \\
CJO & 39.9250 \\
\hline
\end{tabular}

Bomb Calorimeter and Fourier Transform Infrared Spectroscopy (FTIR) were used in order to study the characterization of all samples which were conventional diesel, B5, B5P5, and B5P10. A 
bomb calorimeter is a device used to assess the heat or energy content produced based on the combustion of ASTM D4809 related liquid hydrocarbon fuels. The calorific value is the amount of heat that is transferred to the chamber during combustion. The other function of calorific value is to determine the validity of the mixture alternatively to conventional diesel. The calorific values of CJO, conventional diesel, B5, B5P5 and B5P10 are tabulated in Table 4.

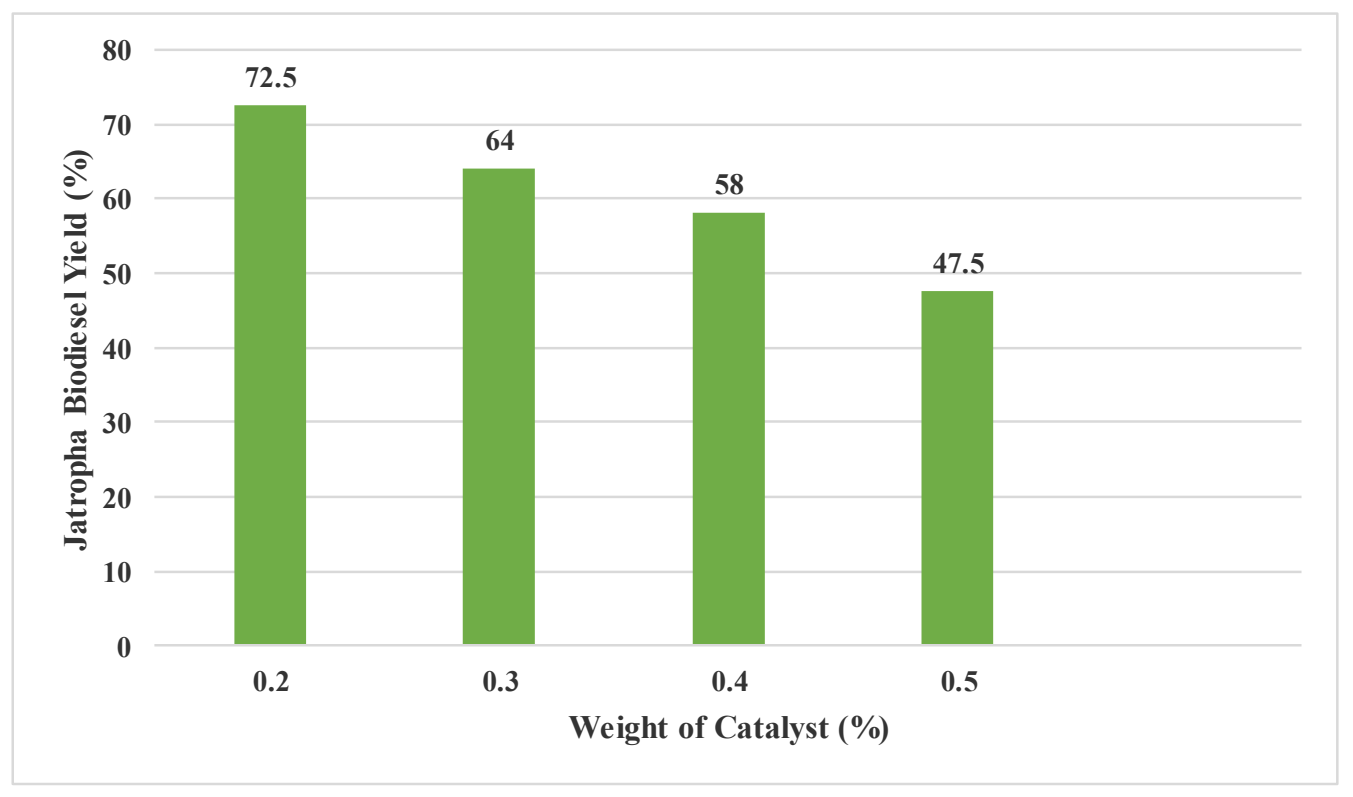

Figure 3. Jatropha biodiesel yield (\%) against the weight of catalyst (\%).

The calorific value of conventional diesel was the highest, followed by CJO, B5P10, B5P5 and B5. This indicated that Jatropha Biodiesel and Jatropha Biodiesel with propanol as an additive had a lower caloric value than the conventional fuel. In addition, as the amount of Jatropha biodiesel was higher in the blend, the calorific value decreased. This happened due to the higher oxygen content of Jatropha biodiesel compared to conventional diesel. Bhuiya et al. (2016) reported that the oxygen content was around $10 \%$ to $11 \%$ [9]. Hence, the concentration of carbon and hydrogen in the mixture reduced which were the thermal energy sources. Moreover, a greater percentage of the fuel blend additive significantly reduced the calorific value. The calorific value of the fuel blends was lower as their compositions consisted of an additional functional oxygen group compared to conventional diesel as shown in Figure 4.

FTIR was done in order to determine the functional group of test fuels by acquiring their absorption spectrum in infrared. Each of the functional groups had its own peak values that eventually reflected the type of vibration, type of bond, and functional group. These appeared in the IR spectrum at the same places. In this study, three types of test fuels that ranged from $600 \mathrm{~cm}^{-1}$ to $4000 \mathrm{~cm}^{-1}$ were evaluated at wave level. Each of the characteristic absorptions reflected the functional group, type of vibration and intensity. Figures 5 to 8 show the graphs of FT-IR spectrum data of conventional diesel, $\mathrm{B} 5, \mathrm{~B} 5 \mathrm{P} 5$ and B5P10. 


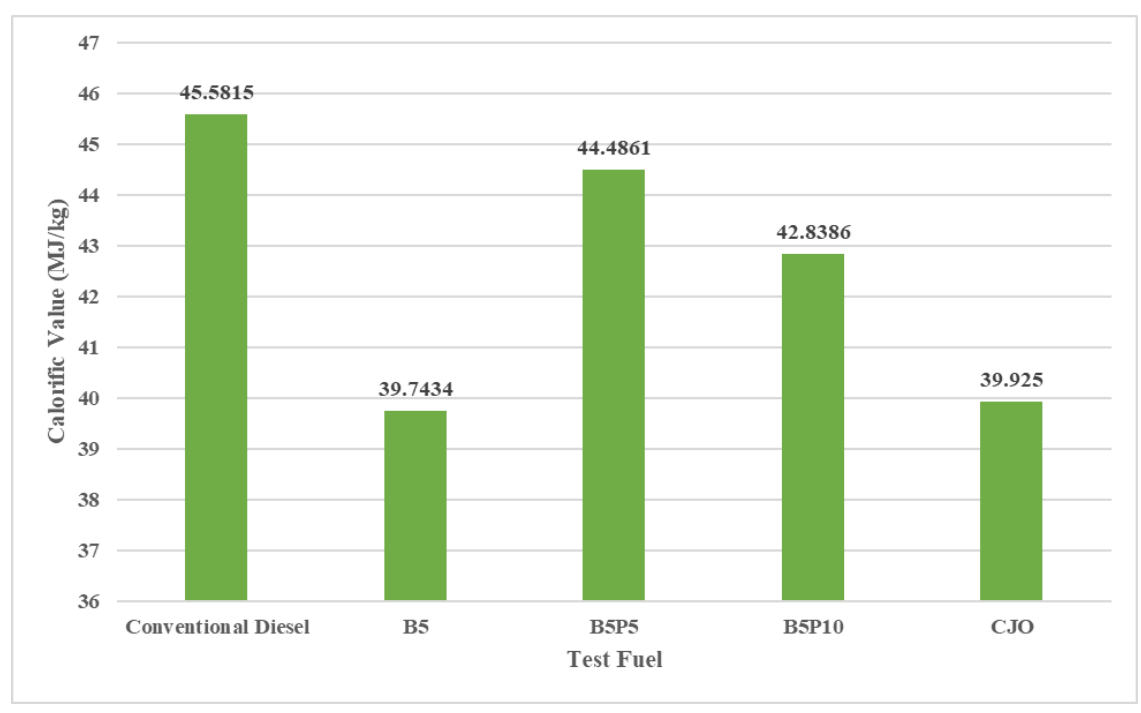

Figure 4. Calorific value $(\mathrm{MJ} / \mathrm{kg})$ against Test Fuels

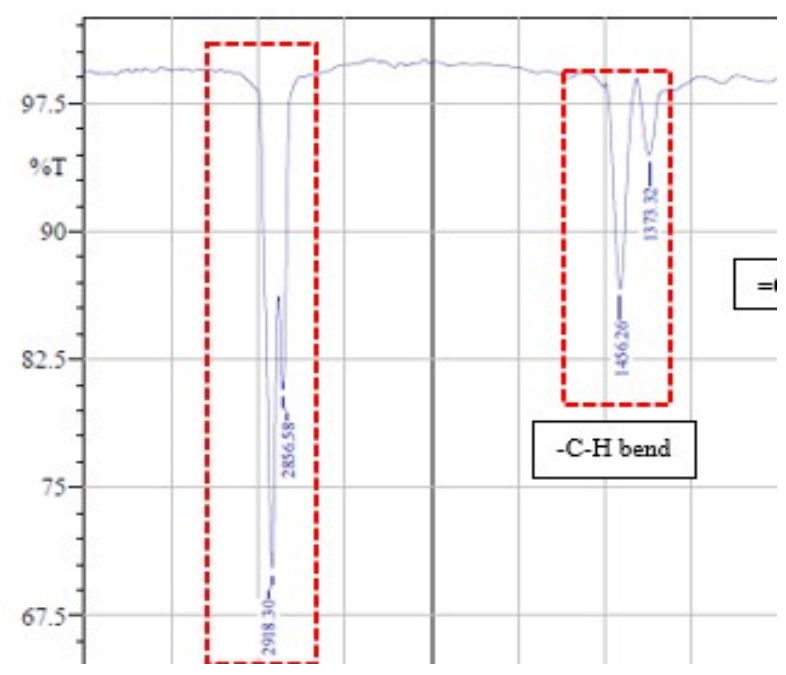

Figure 5. The Infrared spectrum of diesel.

The peak indicating low transmittance was centred on the FT-IR spectrum data. The proportion should be highly absorbent and concentrated. Firstly, for conventional diesel, high absorbance and strong intensity peaks at $2856.58 \mathrm{~cm}-1$ to $2918.30 \mathrm{~cm}^{-1}$ represented C-H stretching. Next, peaks at $1373.32 \mathrm{~cm}^{-1}$ to $1456.26 \mathrm{~cm}^{-1}$ represented $\mathrm{C}-\mathrm{H}$ bending while the peak at $731 \mathrm{~cm}^{-1}$ represented $=\mathrm{C}-\mathrm{H}$ bending. $\mathrm{C}-\mathrm{H}$ bond indicated the hydrocarbon. Bending vibrations with the same bonds produced lower energy than stretching vibrations. Based on the infrared spectrum results summary of B5, B5P5 and $\mathrm{B} 5 \mathrm{P} 10$, they showed that all of these consisted of $\mathrm{C}-\mathrm{H}$ bond which was the same as the conventional diesel. It was similar in characteristics. 


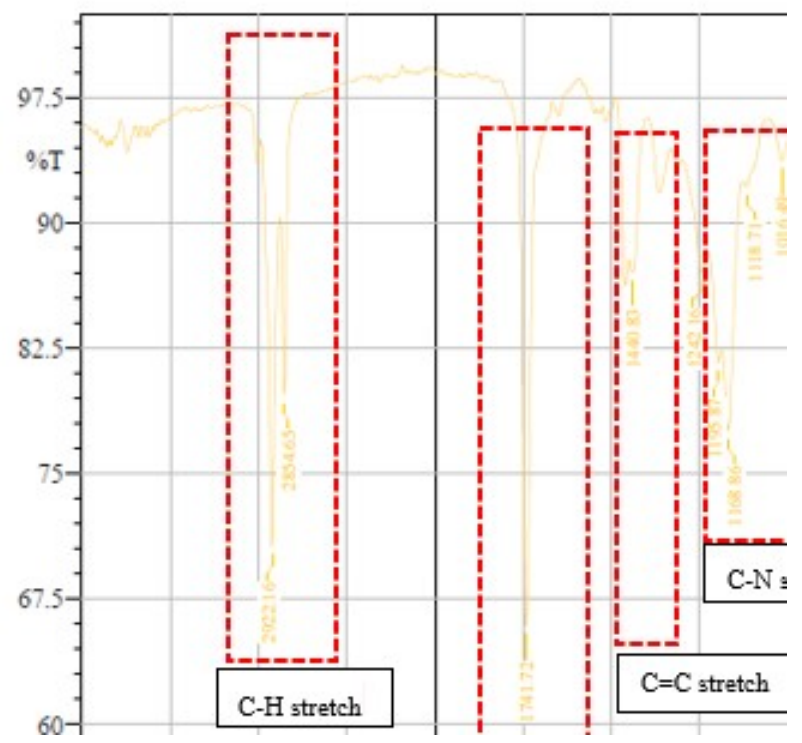

Figure 6. The infrared spectrum of B5.

Furthermore, from the summary Table 5, it proved that the conventional diesel did not have any functional group of the ester, $(\mathrm{C}=\mathrm{O}$ bond $)$ while the other test fuels which were $\mathrm{B} 5, \mathrm{~B} 5 \mathrm{P} 5$ and $\mathrm{B} 5 \mathrm{P} 10$ consisted of the functional group of an ester $(\mathrm{C}=\mathrm{O}$ bond $)$. The peaks of $\mathrm{C}=\mathrm{O}$ for $\mathrm{B} 5, \mathrm{~B} 5 \mathrm{P} 5$ and $\mathrm{B} 5 \mathrm{P} 10$ were $1741.72 \mathrm{~cm}^{-1}, 1165 \mathrm{~cm}^{-1}$ and $1741.72 \mathrm{~cm}^{-1}$ respectively. In addition, B5P5 and B5P10 also had an $\mathrm{O}-\mathrm{H}$ bond. This was also contributed by propanol as it is an alcohol. By having this functional group, it explained the presence of oxygen. Since they contained oxygen, combustion of fuel was more effective, which reduced hydrocarbons in exhaust gases.

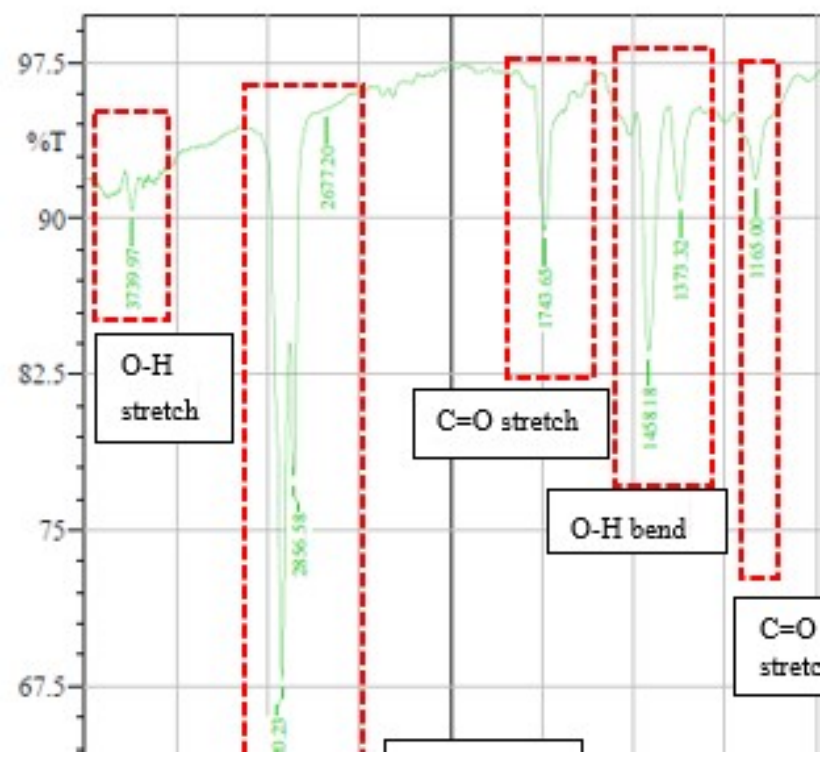

Figure 7. The infrared spectrum of B5P5. 
Table 5. Summary of FT-IR results.

\begin{tabular}{|c|c|c|c|}
\hline Type of fuel & Frequency $\left(\mathrm{cm}^{-1}\right)$ & Functional Group & Type of Vibration \\
\hline \multirow{3}{*}{$\begin{array}{l}\text { Conventional } \\
\text { Diesel }\end{array}$} & $2856.58-2918.30$ & $\mathrm{C}-\mathrm{H}$ & Stretch \\
\hline & $1373.32-1456.26$ & $-\mathrm{C}-\mathrm{H}$ & Bend \\
\hline & 731 & $=\mathrm{C}-\mathrm{H}$ & Bend \\
\hline \multirow[t]{5}{*}{ B5 } & $2854.65-2922.16$ & $\mathrm{C}-\mathrm{H}$ & Stretch \\
\hline & 1741.72 & $\mathrm{C}=\mathrm{O}$ & Stretch \\
\hline & 1440.83 & $\mathrm{C}=\mathrm{C}$ & Stretch \\
\hline & $1016.49-1168.86$ & $\mathrm{C}-\mathrm{N}$ & Stretch \\
\hline & 723.31 & $=\mathrm{C}-\mathrm{H}$ & Bend \\
\hline \multirow[t]{6}{*}{ B5P5 } & 3739.97 & $\mathrm{O}-\mathrm{H}$ & Stretch \\
\hline & $2856.58-2920.23$ & $\mathrm{CH}$ & Stretch \\
\hline & 1743.65 & $\mathrm{C}=\mathrm{O}$ & Stretch \\
\hline & $1373.32-1458.18$ & $\mathrm{O}-\mathrm{H}$ & Bend \\
\hline & 1165 & $\mathrm{C}=\mathrm{O}$ & Stretch \\
\hline & 727.16 & $=\mathrm{C}-\mathrm{H}$ & Bend \\
\hline \multirow[t]{7}{*}{ B5P10 } & $3296.35-3739.97$ & $\mathrm{O}-\mathrm{H}$ & Stretch \\
\hline & $2856.58-2929.23$ & $\mathrm{C}-\mathrm{H}$ & Stretch \\
\hline & 1741.72 & $\mathrm{C}=\mathrm{O}$ & Stretch \\
\hline & $1373.32-1456.26$ & $\mathrm{O}-\mathrm{H}$ & Bend \\
\hline & $1126.43-1163.08$ & $\mathrm{C}=\mathrm{O}$ & Stretch \\
\hline & 950.91 & $\mathrm{O}-\mathrm{H}$ & Bend \\
\hline & 727.16 & $=\mathrm{C}-\mathrm{H}$ & Bend \\
\hline
\end{tabular}

Moreover, the intensity of these bonds was strong. Oxygenates were just pre-used hydrocarbons having a structure that provided a reasonable antiknock value. An oxygenated structure would improve the efficiency of transferring potential energy from combustion to power. Thus, biodiesel was burning more fully and thus increasing the efficiency of combustion. This proved that the Jatropha biodiesel and diesel Jatropha biodiesel blended with propanol were able to improve the performance and emission for diesel engines. 


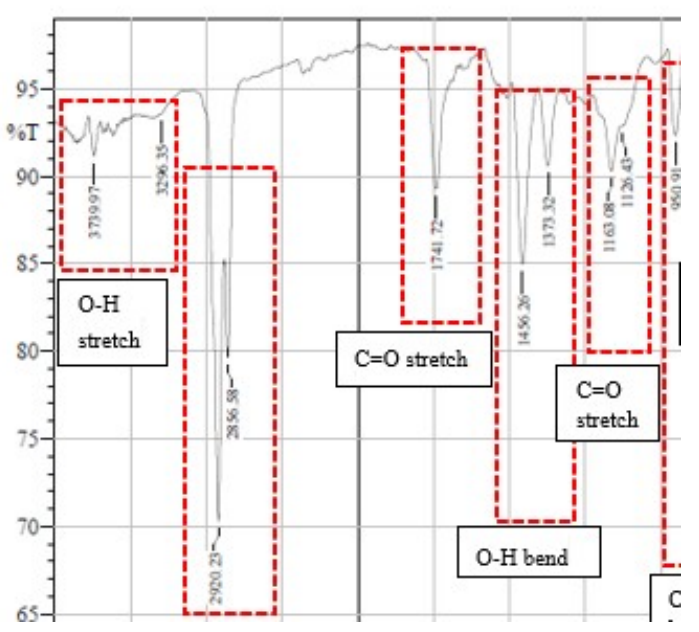

Figure 8. The infrared spectrum of B5P10.

There were three parameters that had been investigated for the performance of diesel engines, namely, brake specific fuel consumption, brake horsepower and mechanical efficiency. The performance of the diesel engine was analyzed at the speed of $1500 \mathrm{rpm}$ until $2000 \mathrm{rpm}$ for 3 minutes. From the diesel engine, power, torque, load, air velocity and temperature could be known. Firstly, brake specific fuel consumption. It was defined as the amount of fuel used in the engine to produce power. For this parameter, it was favourable to have lower specific fuel consumption because it showed that it used less fuel to generate power. Figure 9 illustrates the graph of brake specific fuel consumption versus speed. Low BSFC indicated that the fuel had high fuel efficiency since the engine only consumed little fuel but produced high power. The results showed that an increasing amount of additive would increase the BSFC. This was due to the fact that blends with a higher amount of additive had lower calorific value since they had high containment of oxygen. Low BSFC meant that more fuel was being consumed to produce $1 \mathrm{~kW}$ of power compared to conventional diesel. Even though fuel with a low calorific value produced better combustion, the presence of oxygen took up space in the blend which slightly increased the consumption rate.

Secondly, brake horsepower. Brake horsepower is defined as the rate of work done by a diesel engine. It is the horsepower of a diesel engine without the consideration of frictional loss and parasitic load. The graph in Figure 10 depicts the engine brake horsepower at various speeds for different types of fuels based on the data obtained above. It could be seen that the brake power increased as the engine speed increased. Starting from the speed of $1800 \mathrm{rpm}$ to $2000 \mathrm{rpm}$, diesel showed the highest brake horsepower followed by B5, B5P5 and B5P10. The high BHP of diesel was mainly due to its high heating values and it indicated that fuel had high torque which would produce high engine power. From the analyses done, it could be proven that blends with higher additives contained lower calorific values. Thus, the BHP decreased with an increasing amount of additive in the blended fuel. Apart from that, the decline of BHP was also due to the low cetane number, high viscosity and low torque of the blend fuels. The reduction of brake power and torque would lead to incomplete combustion of fuels in the diesel engine. 


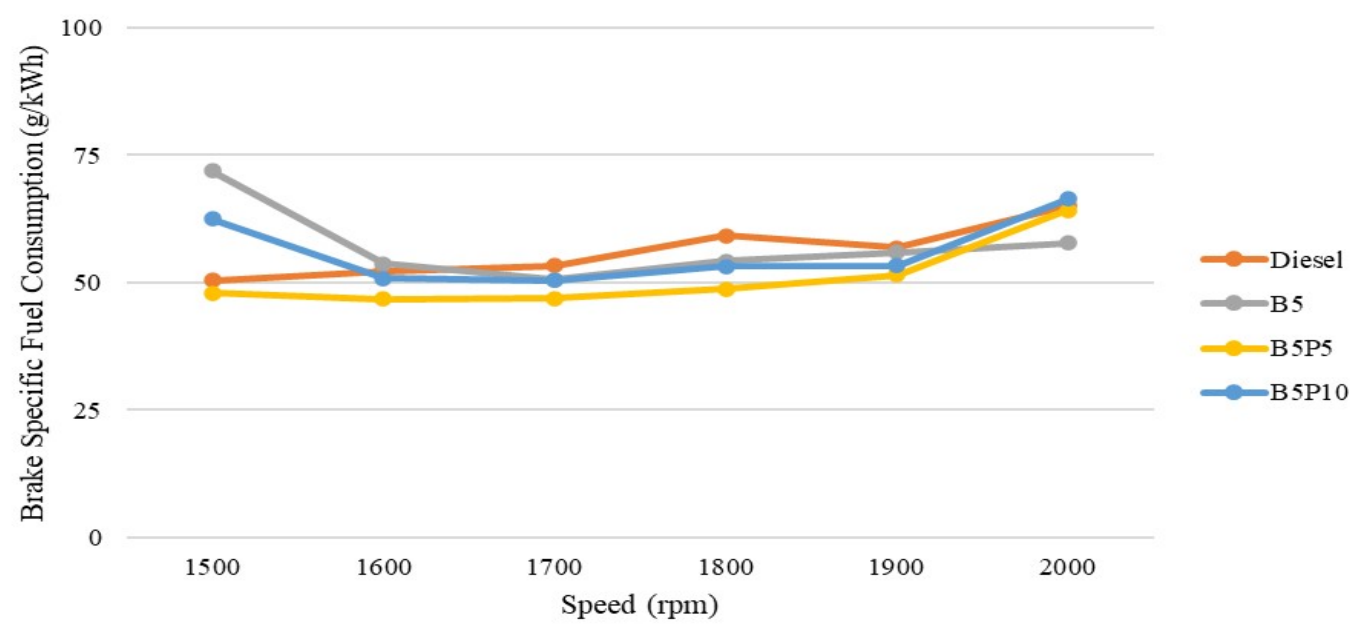

Figure 9. Graph of brake specific fuel consumption versus engine speed of the test fuels

Thirdly, mechanical efficiency. Mechanical efficiency is defined as the effectiveness of a diesel engine to convert the input power into output power. The calculation for mechanical efficiency is the ratio of brake horsepower and indicated horsepower. Based on the data obtained, a graph of mechanical efficiency against speed was plotted. Figure 11 depicts that the highest mechanical efficiency at $2000 \mathrm{rpm}$ (maximum speed) was achieved by B5 at 36.6\% followed by B5P5, Diesel and $\mathrm{B} 5 \mathrm{P} 10$ at $35.8 \%, 35.4 \%$ and $34.7 \%$ respectively. It could be concluded that the presence of propanol as an additive would enhance mechanical efficiency. However, the greater amount of it in the biodiesel blend fuel would indicate a decrease in the performance of an engine.

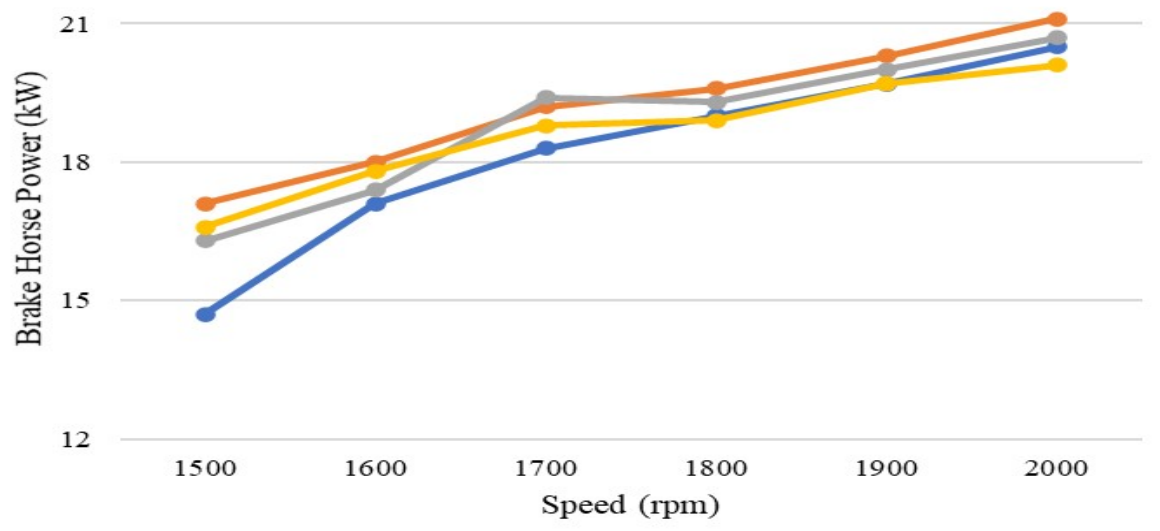

Figure 10. Graph of brake horsepower versus engine speed of the test fuels 


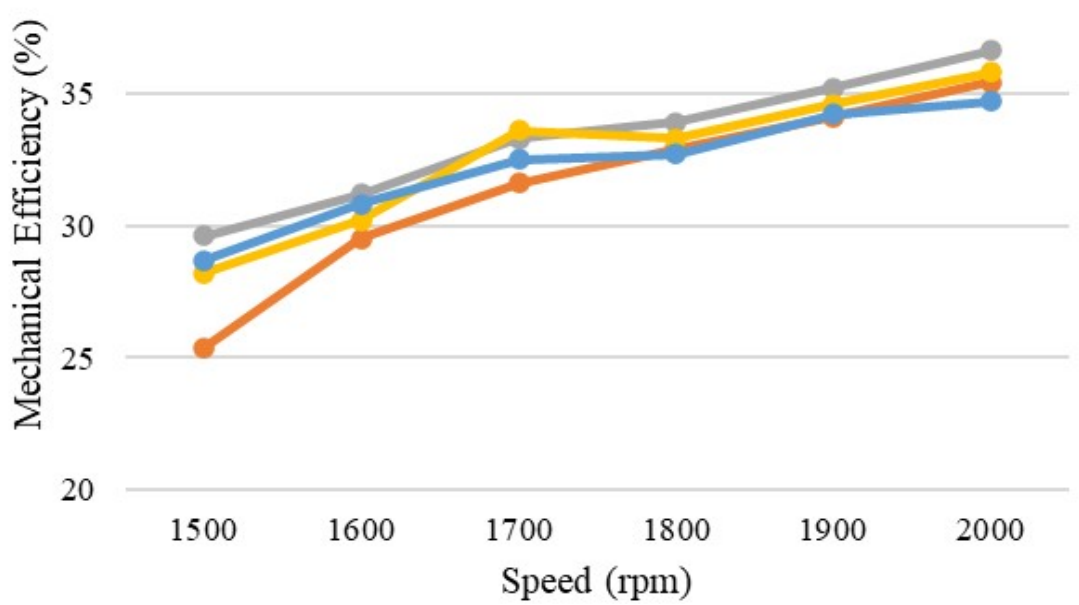

Figure 11. Graph of mechanical efficiency versus engine speed of the test fuels

\section{Conclusion}

It was expected that the Jatropha biodiesel and diesel Jatropha biodiesel blended with propanol might improve the performance and emission characteristics of diesel Jatropha biodiesel blended with propanol at different blending ratios for diesel engines. Jatropha Biodiesel was produced by two-step transesterification. This was because the FFA content of the CJO was more than $3 \%$. Firstly, sulfuric acid $\left(\mathrm{H}_{2} \mathrm{SO}_{4}\right)$ acted as a catalyst in the acid-catalyzed transesterification followed by sodium hydroxide $(\mathrm{NaOH})$ in base-catalyzed transesterification. After acid-catalyzed transesterification, it was found that FFA content could be reduced up to 2.64 as the methanol to oil ratio was 9:1.

Next, different weights of catalyst were tested in base-catalyzed transesterification while using 9:1 methanol to oil ratio. The highest percentage of yield was $72.5 \%$ when the weight of the catalyst was $0.2 \%$. Based on the data obtained, it demonstrated that an increase in the weight of catalyst might reduce the biodiesel yield. Characteristics or properties of the fuels might reflect its effect on the diesel engine such as the performance and emission of biodiesel with additive for diesel engine. The characterization of test fuels was performed by using a bomb calorimeter and FT-IR.

Based on the bomb calorimeter results, it was clear that conventional diesel had the highest value of calorific value which was $45.815 \mathrm{MJ} / \mathrm{kg}$ followed by B5P5, B5P10, CJO and B5. The values of the calorific values were $44.4861 \mathrm{MJ} / \mathrm{kg}, 42.8386 \mathrm{MJ} / \mathrm{kg}, 39.925 \mathrm{MJ} / \mathrm{kg}$ and $39.7434 \mathrm{MJ} / \mathrm{kg}$ respectively. This happened due to the higher oxygen content of Jatropha biodiesel compared to conventional diesel. An increase in oxygen content might contribute to an increase in calorific value. Based on the findings, all test fuels consisted of $\mathrm{C}-\mathrm{H}$ bonds hydrocarbon. By having this functional group, these test fuels could act as fuel for the diesel engine. The Jatropha biodiesel and diesel Jatropha biodiesel blended with propanol could also be used for diesel engines. Besides that, these test fuels excluding the conventional diesel consisted of a $\mathrm{C}=\mathrm{O}$ bond. Not only that, but the $\mathrm{O}-\mathrm{H}$ bond was also present in B5P5 and B5P10. By having this functional group, it explained the presence of oxygen. Since they contained oxygen, the combustion of fuel was more effective, which reduced hydrocarbons in exhaust gases. An oxygenated structure would improve the efficiency of transferring potential energy from combustion to power.

The diesel engine was used to understand and analyze the performance of biodiesel. Three parameters that had been considered were BSFC, BHP and mechanical efficiency. The results showed that increasing the amount of additive would increase the BSFC. This was due to the fact that blends with a higher amount of additive had lower calorific values since they had high containment of oxygen. Not only that, the high BHP of diesel was mainly due to its high heating values and it indicated that fuel had high torque which would produce high engine power. From the analyses done, it could be proven that blends with higher additives contained lower calorific values. Thus, the BHP 
decreased with the increasing amount of additives in the blended fuel. Lastly, the highest mechanical efficiency at $2000 \mathrm{rpm}$ (maximum speed) was achieved by B5 at 36.6\% followed by B5P5, Diesel and $\mathrm{B} 5 \mathrm{P} 10$ at $35.8 \%, 35.4 \%$ and $34.7 \%$ respectively. It could be concluded that the presence of propanol as an additive would enhance mechanical efficiency. However, a greater amount of it in biodiesel blend fuel would indicate a decrease in engine performance.

Hence, biodiesel was burning more fully and eventually increased the efficiency of combustion. This proved that the Jatropha biodiesel and diesel Jatropha biodiesel blended with propanol were able to improve the performance and emission for diesel engines. In short, the benefits of biodiesel included liquid functionality of existence, greater availability, environmental friendliness, higher efficiency in combustion, less sulfur and aromatic content, and low toxicity.

\section{Acknowledgements}

The authors would like to acknowledge the Faculty of Engineering, Universiti Malaysia Sarawak (UNIMAS), 94300 Kota Samarahan, Sarawak, Malaysia and the School of Engineering and Technology, University College of Technology Sarawak (UCTS), 96000 Sibu, Sarawak, Malaysia for the support.

\section{References}

[1] Gude, V. G., \& Grant, G. (2019). Sustainable Biodiesel Production. 889. https://doi.org/10.3390/wsf200889

[2] Kannahi, M., \& Arulmozhi, R. (2013). Production of biodiesel from edible and non-edible oils using Rhizopus oryzae and Aspergillus niger. Asian J Plant Sci Res, 3, 60-64. ISSN: 2249-7412

[3] Ogunwole, O. A. (2012). Production of biodiesel from jatropha oil (curcas oil). Research Journal of Chemical Sciences, 2(11), 30-33. ISSN: 2249-9261

[4] Perera, F. (2018). Pollution from fossil-fuel combustion is the leading environmental threat to global pediatric health and equity: Solutions exist. International journal of environmental research and public health, 15(1), 16. https://doi.org/10.3390/ijerph15010016

[5] Aydin, K., Sarıbıyı, O. Y., Özcanl1, M., Serin, H., \& Serin, S. (2010). Biodiesel Production from Ricinus Communis Oil and Its Blends with Soybean Biodiesel. Strojniski Vestnik/Journal of Mechanical Engineering, 56(12). DOI:10.5545/sv-jme.2009.054

[6] Shahid, E. M., Jamal, Y., Shah, A. N., Rumzan, N., \& Munsha, M. (2012). Effect of used cooking oil methyl ester on compression ignition engine. Journal of Quality and Technology Management, 8(2), 91100. https://doi.org/10.1016/j.eps1.2014.02.047

[7] Grebemariam, S., \& Marchetti, J. M. (2017). Biodiesel production technologies: A review. AIMS Energy, 5(3), 425-457 DOI: 10.3934/energy.2017.3.425

[8] Farouk, H., Jaafar, M. N. M., \& Atabani, A. E. (2014). A study of biodiesel production from crude jatropha oil (CJO) with high level of free fatty acids. Jurnal Teknologi (Sciences and Engineering), 69(3), 65-72. https://doi.org/10.11113/jt.v69.3145

[9] Bhuiya, M. M. K., Rasul, M. G., Khan, M. M. K., Ashwath, N., Azad, A. K., \& Hazrat, M. A. (2016). Prospects of 2nd generation biodiesel as a sustainable fuel - Part 2: Properties, performance and emission characteristics. Renewable and Sustainable Energy Reviews, 55, 1129-1146. https://doi.org/10.1016/j.rser.2015.09.086 